\title{
Evaluation of alternative solvents for improvement of oil extraction from rapeseeds
}

\author{
Ying Li ${ }^{a}$, Frédéric Fine ${ }^{b}$, Anne-Sylvie Fabiano-Tixier ${ }^{a, *}$, Maryline Abert-Vian $^{a}$, \\ Patrick Carre ${ }^{c}$, Xavier Pages ${ }^{\mathrm{d}}$, Farid Chemat $^{\mathrm{a}}$ \\ ${ }^{a}$ GREEN Extraction Team, Université d'Avignon et des Pays de Vaucluse, INRA, UMR 408, 33, rue Louis-Pasteur, 84000 Avignon, France \\ ${ }^{\mathrm{b}}$ CETIOM, Technical institute for oil seeds, 11, rue Monge, 33600 Pessac, France \\ ${ }^{\mathrm{c}}$ CREOL, 11, rue Monge, 33600 Pessac, France \\ ${ }^{\mathrm{d}}$ ITERG, 11, rue Monge, 33600 Pessac, France
}

Keywords:

Alternative solvents

Edible oil

Micronutrients

Soxhlet extraction

Hansen solubility parameters

\section{A B S T R A C T}

This present study was designed to evaluate the performances of five alternative solvents (alcohols: ethanol, isopropanol and terpenes: D-limonene, $\alpha$-pinene, $p$-cymene) compared to $n$-hexane in rapeseed oil extraction. The extracted oils were quantitatively and qualitatively analyzed to compare the solvents' performances in terms of kinetics, fatty acid compositions, lipid yields, and classes. Moreover, micronutrients in extracted oils were also respectively quantified by high-performance liquid chromatography (HPLC) and gas chromatography (GC). In addition, the interactions between alternative solvents and rapeseed oil have been theoretically studied with the Hansen solubility methodology to get a better comprehension of dissolving mechanisms. The results indicated that $p$ cymene could be the most promising solvent for $n$-hexane substitution with higher lipid yield and good selectivity, despite the micronutrient contents were relatively low.

\section{R É S U M É}

L'objectif de cette étude vise à évaluer les performances de cinq solvants alternatifs (deux alcools : éthanol, isopropanol, et les terpènes, D-limonène, $\alpha$-pinène, $p$-cymène) par rapport au $n$-hexane pour l'extraction de l'huile de colza. Les huiles extraites à l'aide de ces différents solvants ont été analysées quantitativement et qualitativement afin de comparer à la fois les cinétiques d'extraction, la composition en acides gras de ces dernières, ainsi que les rendements lipidiques. En outre, les micronutriments présents dans les huiles extraites ont été également quantifiés à la fois par chromatographie en phase liquide à haute performance (HPLC) et par chromatographie en phase gazeuse (CPG). De plus, les interactions entre les solvants alternatifs et l'huile de colza ont été étudiées théoriquement à l'aide de la méthodologie de solubilité de Hansen afin d'essayer de mettre en avant une meilleure compréhension des mécanismes de dissolution. Les résultats indiquent que le $p$-cymène pourrait être le solvant le plus prometteur pour la substitution du $n$-hexane, avec un rendement lipidique élevé et une bonne sélectivité, malgré une teneur en micronutriments relativement faibles.

\footnotetext{
* Corresponding author.

E-mail address: anne-sylvie.fabiano@univ-avignon.fr (A.-S. Fabiano-Tixier).
} 
Version définitive du manuscrit publiée dans / Final version of the manuscript published in :

Comptes Rendus Chimie (2014), Vol. 17, p. 242-25, DOl: 10.1016/j.crci.2013.09.002

Journal homepage: www.sciencedirect.com

\section{Introduction}

Over the last five decades, the industrial oil extraction process has changed little, though there have been several technical developments with regard to its optimization and a better control. The conventional process procedure involves three main successive unit operations, as shown in Fig. 1. Seed preparation includes cleaning, pre-heating $\left(50-80^{\circ} \mathrm{C}\right)$, crushing and cooking (prepared seed flakes from previous steps undergo indirect steaming at 90$110{ }^{\circ} \mathrm{C}$, which causes a $1-3 \%$ loss of water content). Mechanical extraction makes a press cake, also called “oilcake", containing 16-24\% of oil after continuous pressing, which depends on the variety of the treated seeds. The following solvent extraction from ground oilcakes is achieved by a counter-flow current extraction using $n$-hexane as a solvent. The extraction meal is desolventized by desorption and evaporation of hexane through direct and indirect steam injection. The oils are recovered by distillation of miscella, which allows evaporation of volatile solvents by vacuum steam stripping.

The conventional process utilizes only mechanical extraction (pre-press yields about $60 \%$ of oil) or solvent extraction, or even combines both of them [1]. In order to become edible, the crude vegetable oil, a mixture of pressed and extracted oil, must undergo further refining processes for elimination of impurities and contaminants, in order to guarantee physicochemical and organoleptic properties that fitted to the requirements of downstream users. The processing methods developed over the years have been designed to reduce operating costs, to maximize the oil yields and solvent recovery, as well as the preservation of crude oil quality by avoiding enzymatic and oxidative degradation. Some influencing factors in extraction processes have been previously studied, e.g., the nature of solvents [2], the particle size [3] and extraction conditions such as temperature, pressure, etc. [4]. Above

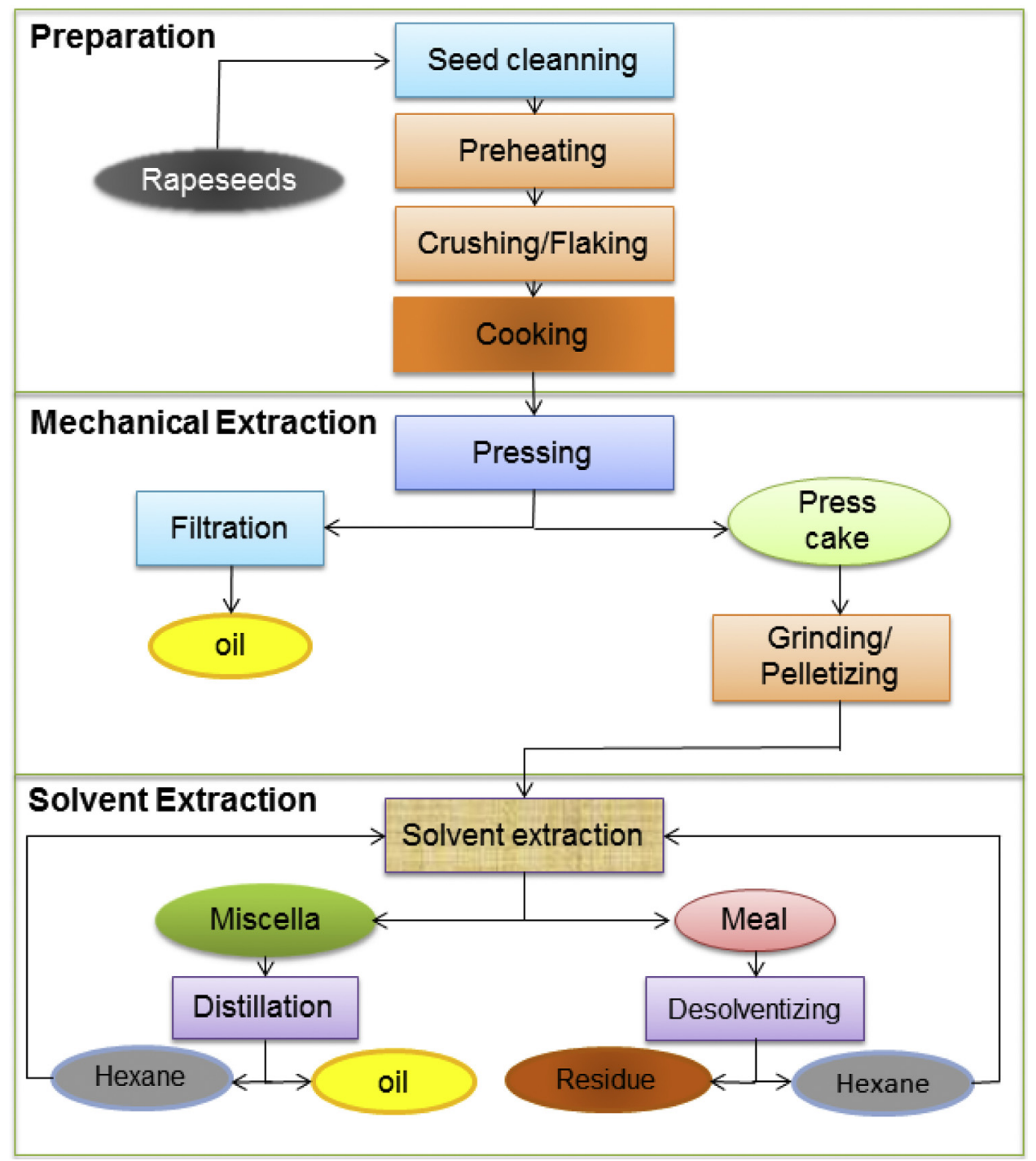

Fig. 1. Conventional processing procedures for rapeseed oil extraction. Color online. 
all, the optimal conditions for oil extraction from rapeseed and other seeds have been determined.n-Hexane, which has a relatively low boiling point $\left(69^{\circ} \mathrm{C}\right)$, is the commonlyused petroleum-based solvent for extraction of vegetable oils. It has been selected as an excellent extraction solvent for many years due to its nonpolar properties and simple recovery. In addition, it presents a high selectivity to oils and a rather low latent heat of vaporization $(330 \mathrm{~kJ} / \mathrm{kg})$, which allows easy evaporation, efficient extraction and limited energy cost. The use of $n$-hexane in solvent extraction outperforms mechanical extraction in terms of oil yield and quality. The residues after solvent extraction have an oil content of less than $3 \%$ compared to $8-9 \%$ in press cakes at the same mild operating temperature, whereas higher temperatures are required to maximize oil yield only in mechanical extraction.

Despite the advantage of using $n$-hexane in solvent extraction, questions may arise due to its negative influence on human health and environment. Its leakage during extraction and recovery has been identified as an air pollutant since it can react with other pollutants to produce ozone and photochemical oxidants [5]. It has been considered as a harmful substance with several classifications: highly flammable $(\mathrm{F})$; reproductive toxicant in three categories, harmful (Xn), irritant (Xi), and dangerous for the environment $(\mathrm{N})$. A long-term exposure to commercial-grade $n$-hexane (40-60\%) may cause disorders of central nervous system and fertility problems. Thus, it is compulsory to establish special precautions for labors during their operation in industry, especially for the working areas with explosion risk. It should be remembered that the use of $n$-hexane in oil and fat extraction is regulated regarding the quantity of consumed hexane per ton of crushed seeds. Although $n$ hexane extraction is considered as a Best Available Technology Not Entailing Excessive Costs (BATNEEC) by numerous environment regulation authorities, concerns with safety, environment and health have nowadays led to a new hotspot in exploring alternative solvents to hexane in order to reduce its emissions and negative effects. As the results of this new trend for environment protection and development of green chemistry, such solvent should be gradually substituted by alternative solvents that are recognized as economically viable and environmentally safe.

In this study, several alternative solvents (ethanol, butanol, isopropanol, D-limonene, $\alpha$-pinene and $p$-cymene) have been used to replace $n$-hexane as a solvent used in the extraction of oil from rapeseeds. The performances of these solvents in the enhanced extraction (extraction kinetics, quantity and quality of extracted oils) were experimentally studied in comparison with that of the reference solvent ( $n$-hexane) in original extraction, as well as their processing procedures. More comparisons between different solvents on micronutrients (tocopherols, tocotrienols, and sterols) have also been studied regarding their content in extracted oils. Besides, introduction of the Hansen solubility parameters (HSP) prediction model has been highlighted as a heuristic tool for better explanation of dissolving mechanisms and appropriate selection of green alternative solvents.

\section{Materials and methods}

\subsection{Materials and reagents}

Rapeseeds, belonging to Astrid variety, were provided by the Centre technique interprofessionnel des oléagineux et du chanvre (CETIOM, Pessac, France). Isopropanol, butanol, D-limonene, $\alpha$-pinene, and $p$-cymene (analytical grade) were purchased from Sigma (USA). Ethanol, $n$-hexane, methanol, sulfuric acid, sodium chloride, chloroform, methyl acetate, acetic acid, diethyl ether and potassium chloride were of analytical grade and were supplied by VWR International (Darmstadt, Germany).

\subsection{Experimental procedures}

Rapeseeds were coarsely ground less than $30 \mathrm{~min}$ before the extraction. The moisture level of rapeseeds was determined using a MB35 moisture analyzer (Ohaus, Nänikon, Switzerland). The moisture content was measured in triplicate and the mean value (8.69\%) was used for the following calculations.

Oils were isolated from rapeseeds by means of an improved Soxhlet extraction. Fifteen grams of coarsely ground rapeseeds were weighed and transferred into a $30 \mathrm{~mm} \times 80 \mathrm{~mm}$ cellulose thimble (Macherey-Nagel, Germany), which was plugged with cotton in order to avoid transfer of sample particles in the distillation flask. They were then placed in the extraction chamber of a $200 \mathrm{~mL}$ Soxhlet apparatus fitted with a condenser, which was placed on a $500-\mathrm{mL}$ distillation flask containing $300 \mathrm{~mL}$ of solvents (D-limonene, $\alpha$-pinene, $p$-cymene, $n$-hexane, ethanol, isopropanol or butanol, respectively). Rapeseeds were then extracted under reflux with $n$-hexane for $6 \mathrm{~h}$ (812 cycles/h).

After the extraction, when using $n$-hexane, ethanol, isopropanol or butanol, the content of distillation flask was evaporated with a vacuum rotary evaporator. The flask was then weighed and this operation repeated until the difference between two consecutive weights was less than $10 \%(w / w)$. The weight of rapeseed oil was determined and then used for calculating the yield of extracted oil. In the case of terpene solvents, removal of solvent has been done by Clevenger distillation. The Soxhlet apparatus was replaced by a Clevenger glassware on the distillation flask. Distilled water was added to the mixture of extracted oils and terpene solvents prior to the distillation. During azeotropic distillation of the binary water-terpene mixture at less than $100^{\circ} \mathrm{C}$, terpene solvents and extracted oils have been recovered respectively in the outside (upper phase) and inside (down phase) of the Clevenger glassware from water layer through phase separation.

In fact, the difficulty of the evaporation depends directly on the solvent type. In order to resolve this problem in terms of energy and temperature, it is necessary to know from which plant these alternative solvents have been extracted. Terpenes are the primary constituents in the essential oils that are commonly extracted from many types of plant matrices by hetero-azeotropic distillation using water. The 
Clevenger apparatus has been used in hydrodistillation for decades with the aim of extracting and measuring essential oils contained in plants [6]. This process allows the extraction of compounds at $97-98^{\circ} \mathrm{C}$ at atmospheric pressure and even at a lower one if it is applied regardless of the high boiling point $\left(150-300{ }^{\circ} \mathrm{C}\right)$ of the terpenes contained in essential oils. Therefore, this apparatus can be used for the recovery of terpenes resulting from the extraction step of oil from rapeseeds, such as D-limonene, $\alpha$-pinene, and $p$-cymene.

Conventional Soxhlet extraction of rapeseed oil was performed using a 15-g sample after fine grinding (particle size: $200-400 \mu \mathrm{m}$ ) [7]. Samples were extracted under reflux with $n$-hexane during $4 \mathrm{~h}$ (18-22 cycles/h). Thereafter, the cellulose thimble was cooled to room temperature in a desiccator and its content was then ground before being loaded again in the cellulose cartridge. The described procedure was thus repeated during $2 \mathrm{~h}$ until a total extraction time of $8 \mathrm{~h}(4 \mathrm{~h}+2 \mathrm{~h}+2 \mathrm{~h})$. All extractions were performed in triplicate and the mean values were reported. Results were obtained by gas chromatography analysis in order to obtain the yields of extracted oils. The yield of extracts was expressed as a percentage of the weight of extracts obtained after extraction relative to the weight of dry rapeseeds used for extraction, as described hereinafter.

$$
\begin{aligned}
& \text { yield of extracts }(\%) \\
& \qquad=\frac{\text { weight of extracts obtained after extraction }}{\text { weight of rapeseeds(dry materials })} \times 100
\end{aligned}
$$

For kinetics study, $1 \mathrm{~mL}$ of sample was collected from the extractor after the first, the second, the third and the fourth siphoning, then the same volume of sample was withdrawn every 30 min until a total extraction time of $3 \mathrm{~h}$, and then every hour until a total extraction time of $6 \mathrm{~h}$ (instead of 8 hours for the conventional method). Each sample was then put in an oven at $37{ }^{\circ} \mathrm{C}$ during 72 hours for evaporation.

\subsection{Chromatographic analysis}

The lipids and other constitutes in extracted oils were quantitatively and qualitatively analyzed according to respective norms: AOCS official methods Ca $5 a-40$ for free fatty acids, AOCS official methods Ce 1-62 and Ce 2-66 for mono-, di- and tri-glycerides, NF EN ISO 12228 for sterols, and NF EN ISO 9936 for tocopherol and tocotrienol [8].

Fatty acids methyl esters (FAMEs) were separated, identified and quantified by gas chromatography coupled with a flame ionization detector (GC-FID). Samples were prepared from extracted oils using acid-catalyzed transmethylation as described in Li et al. [9]. One milliliter of methanolic sulfuric acid $(5 \% \mathrm{v} / \mathrm{v})$ was added to a specific amount of extracted oils. The mixture was then heated at $85^{\circ} \mathrm{C}$ for $90 \mathrm{~min}$ and then removed from the heater; $1.5 \mathrm{~mL}$ of a $(0.9 \%)$ sodium chloride solution and $1 \mathrm{~mL}$ of $n$-hexane were added afterwards. The flask was stoppered and shaken vigorously during 30 seconds before centrifugation at $4000 \mathrm{rpm}$ for 2 minutes. A small amount of the organic layer was removed and transferred in a vial before being injected directly in a gas chromatographer.

Analyses were performed by a $7820 \mathrm{~A}$ GC system (Agilent technologies, USA) equipped with a FID detector and an auto-sampler. Gas chromatography was performed by a BD-EN14103 capillary column $(30 \mathrm{~m} \times 0.32 \mathrm{~mm} \times$ $0.25 \mu \mathrm{m}$ ) using helium as a carrier gas at the velocity of $33 \mathrm{~cm} / \mathrm{s}$. Two microliters of various samples were injected in split mode (split ratio: $1: 20$ ) at $250{ }^{\circ} \mathrm{C}$. The oven temperature program was operated as follows: initial temperature at $50{ }^{\circ} \mathrm{C}$ for one minute, then increase at $20^{\circ} \mathrm{C} /$ min to $180^{\circ} \mathrm{C}$ and at $2{ }^{\circ} \mathrm{C} / \mathrm{min}$ from $180^{\circ} \mathrm{C}$ to $230{ }^{\circ} \mathrm{C}$, then the flask was held isothermally at $230^{\circ} \mathrm{C}$ for $10 \mathrm{~min}$. Data were collected with Agilent EZChrom Elite software. FAMEs were identified comparison with purified FAME standards (Sigma Co., USA).

\subsection{Solubility prediction methods}

Solubility parameters of solvents have been studied by means of HSP theoretical prediction [10]. HSP provides a convenient and efficient way to characterize solutesolvent interactions according to the classical "like dissolves like" rule. HSP was based on the concept that the total cohesive energy density is approximated by the sum of the energy densities required to overcome atomic dispersion forces $\left(\delta_{\mathrm{d}}{ }^{2}\right)$, molecular polar forces arising from dipole moments $\left(\delta_{\mathrm{p}}{ }^{2}\right)$ and hydrogen bonds (exchange of electrons, proton donor/acceptor) between moleculars $\left(\delta_{\mathrm{h}}{ }^{2}\right)$, as given in the following equation:

$\delta_{\text {total }}^{2}=\delta_{\mathrm{d}}^{2}+\delta_{\mathrm{p}}^{2}+\delta_{\mathrm{h}}^{2}$

where $\delta_{\text {total }}$ is the Hansen total solubility parameter, which now consist of its three partitioned solubility parameters in terms of dispersion $\left(\delta_{d}\right)$, polar $\left(\delta_{p}\right)$ and hydrogenbonding $\left(\delta_{h}\right)$ forces.

In general, the more similar the two $\delta_{\text {total }}$ are, the greater the affinity between solute and solvent. The chemical structures of the solvents and solutes discussed in this article could be mutually transformed by JChemPaint ver. 3.3 to their simplified molecular input line entry syntax (SMILES) notations, which were subsequently used to calculate the solubility parameters of various solvents and constituents in extracted oil. These solubility parameters were further modeled to a frequently used twodimensional HSP sphere for better visualizing the solute/ solvent interaction because of insignificant differences between $\delta_{\mathrm{d}} \mathrm{s}$ (HSPiP Version 4.0, Denmark).

\section{Results and discussion}

\subsection{Oil extraction yield}

Rapeseed samples had a mean oil content of 44-45\%, with a standard deviation of $1 \%$ (wt \%), which was dependent on the harvest year. The yield of extracted oils corresponding to different solvents was determined by GC-FID analysis (results are listed in Table 1). The yield of $n$-hexane-extracted oils was similar to that mentioned in the norm ISO 659-1988. The highest oil yield was obtained 
Version définitive du manuscrit publiée dans / Final version of the manuscript published in :

Comptes Rendus Chimie (2014), Vol. 17, p. 242-25, DOI: 10.1016/j.crci.201.3.09.002

Journal homepage: www.sciencedirect.com

Table 1

Extracted rapeseed oil yields with various solvents.

\begin{tabular}{lll}
\hline Solvent & $\begin{array}{l}\text { Oil yields } \\
\text { (\% of dry mass) }\end{array}$ & $\begin{array}{l}\text { Percentage of lipids extracted from those } \\
\text { initially present in the rapeseed (\%) }\end{array}$ \\
\hline$n$-Hexane & 25.02 & 58.2 \\
Ethanol & 9.79 & 22.8 \\
Isopropanol & 35.74 & 83.1 \\
Butanol & 33.67 & 78.3 \\
p-Cymene & 38.22 & 88.9 \\
$\alpha$-Pinene & 28.18 & 65.5 \\
Limonene & 37.74 & 80.8
\end{tabular}

* ISO 659-1988.

using $p$-cymene as a solvent, followed by using $\mathrm{D}$ limonene, isopropanol, butanol, $\alpha$-pinene, $n$-hexane, and ethanol, respectively. This result could be explained by the difference between solvent polarities. Terpenes and alcohols are generally more polar than $n$-hexane. However, ethanol gave a lowest oil yield due to its inefficient solvation. It was also interesting to observe that $p$ cymene, D-limonene and isopropanol were the most effective solvents for oil extraction from the original rapeseed, and $p$-cymene, isopropanol and $n$-hexane were more selective.

As a result of grinding, plant cell walls were partially destroyed and the solvent penetrations into the cells depended on the solvent affinity to materials. Terpene solvents could penetrate the cell wall at the globule level. A higher dissolving ability of terpenes for lipids might be pointed out with a higher boiling temperature, which led to a lower viscosity of the solvent and a better diffusion rate of the solute from the solid phase to the solvent accordingly. The affinity of ethanol to oil was temperature dependent and the temperature in the extracting cartridge was probably too low to achieve an efficient solvation. Isopropanol and $p$ cymene were finally chosen for further comparison with $n$ hexane as a reference solvent for oil extraction because of their good extractive ability and selectivity.

\subsection{Extraction kinetics}

The overall yield of extracted oils from original rapeseeds using $n$-hexane, isopropanol, and $p$-cymene as

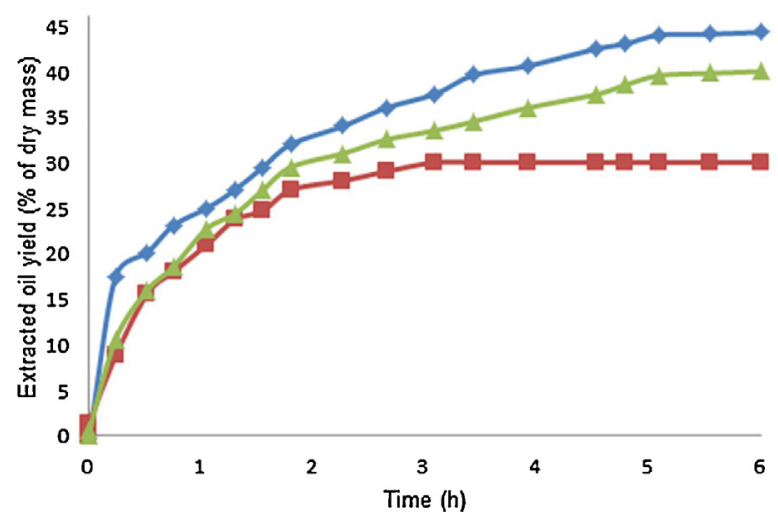

Fig. 2. Kinetics of rapeseed oil extraction with $p$-cymene ( $\bullet)$, isopropanol $(\Delta)$, and $n$-hexane ( $\square$ ). Color online. solvents increased with extraction time (Fig. 2). Although the final yield for $p$-cymene was slightly higher (close to $45 \%)$, there was no significant differences between isopropanol and $p$-cymene in the yield of extracted oils. On the contrary, the final yield of extracted oil using $n$ hexane is significantly lower (around 30\%). Moreover, it was interesting to notice that different performances between $n$-hexane, isopropanol and $p$-cymene were found in spite of their similar yield growth trend. After a onehour solvent heating, the yield of extracted oils remarkably rose up as the extraction time increased. Furthermore, two phases were observed in $n$-hexane extraction kinetics, the first phase (the first $4 \mathrm{~h}$ ) corresponding to the extraction of the broken cells with penetration of $n$-hexane until the residual oil was unavailable for the solvent. It represented a rapid increase in extraction yield to approximately $95 \%$ of the total yield. The second phase ( $4 \sim 6 \mathrm{~h})$ corresponding to horizontal line indicated that the extraction process had been stopped during this period. However, there was only one phase for isopropanol and $p$-cymene under the same extraction conditions. The increasing trend of yield was more linear, and no horizontal trend line was found in this case.

\subsection{Analysis of extracted oils}

\subsubsection{Qualitative analysis of lipids classes}

Relevant components in extracted oils, i.e. TAG (triglycerides), DAG (di-glycerides), MAG (mono-glycerides), FFA (free fatty acids), etc., and their relative proportions were determined by gas chromatographic analysis. As shown in Table 2, TAG, DAG, and FFA were generally the main components in all extracted oils. Because of different solvent polarity, $n$-hexane extracts presented a higher content in triglycerides (99\%), while lower levels were observed in isopropanol and $p$-cymene extracts, with a content of 94.7 and $96.7 \%$, respectively. Nevertheless, isopropanol and p-cymene could extract more polar lipids such as FFA, MAG, and DAG than $n$ hexane. The lipid classes in $n$-hexane-extracted oils were in consistency with the previous study [11]. In addition, it should be mentioned that DAG, MAG and FFA could also be considered as degradation markers of extracted oils that contained a great quantity of TAG.

\subsubsection{The composition of extracted oils}

The rapeseed extracted oils were converted into fatty acids methyl ester (FAME) derivatives and different fatty 
Version définitive du manuscrit publiée dans / Final version of the manuscript published in :

Comptes Rendus Chimie (2014), Vol. 17, p. 242-25, DOl: 10.1016/j.crci.2013.09.002

Journal homepage: www.sciencedirect.com

Table 2

Qualitative analysis of lipid classes in extracted rapeseed oils with $p$ cymene, isopropanol, and $n$-hexane.

\begin{tabular}{llrl}
\hline $\begin{array}{l}\text { Lipid class } \\
\text { composition }\end{array}$ & $n$-Hexane (\%) & Isopropanol (\%) & $p$-Cymene (\%) \\
\hline FFA & $0.1 \pm 0.02$ & $0.4 \pm 0.02$ & $2.0 \pm 0.25$ \\
TAG & $99.0 \pm 0.16$ & $94.7 \pm 0.82$ & $96.7 \pm 0.20$ \\
DAG & $0.5 \pm 0.06$ & $1.4 \pm 0.15$ & $1.0 \pm 0.20$ \\
MAG & Not detected & $3.0 \pm 0.35$ & 0.0 \\
Unindentified & 0.1 & $0.2 \pm 0.01$ & 0.0 \\
\hline
\end{tabular}

FFA: free fatty acid; TAG: triacylglycerol; DAG: diacylglycerol; MAG: monoacylglycerol.

acids in extracted oils were then separated and quantified by GC-FID. The fatty acid composition and their relative proportions in different solvent-extracted oils are summarized in Table 3. There was no significant selectivity between the various solvents because of the same compositions of fatty acids in different solvent-extracted oils. Whichever the solvent used, the main fatty acids in extracted oils were oleic (C18:1), linoleic (C18:2), $\alpha$ linolenic (C18:3) and palmitic (C16:0) acids, which accounted for more than $90 \%$ of the total fatty acids in extracted oils. Other fatty acids such as stearic (C18:0), eicosenoic (C20:1) and erucic (C22:1) acids were also quantified with a less predominant proportion. Furthermore, palmitoleic (C16:1), palmitolenic (C16:2), arachidic (C20:0), eicosadienoic (C20:2), and behenic (C22:0) acids could be identified in trace levels. All chemical structures of these fatty acids described in Fig. 3 and the main fatty acids that constitute the structure of triglycerides were selected for further calculation of HSP. Moreover, the difference between oil compositions was insignificant, even though extraction and evaporation temperatures are greatly different, depending on the boiling point of the solvents. This has also proved that the polyunsaturated fatty acids were not degraded during the extraction process.

\subsubsection{Micronutrient analysis}

The main components of unsaponifiables are tocopherols and sterols, which are present in different amounts in vegetable oils (Fig. 4). Tocopherol and tocotrienol contents in extracted rapeseed oils with three selected solvents were determined by HPLC analysis. Tocopherols are recognized as efficient natural antioxidants and their isomers also have different in vitro and in vivo antioxidant activity. Their content in the plant is probably governed by the content of unsaturated fatty acid. As can be seen in Table 4, the tocopherol content was lower in the oil extracted with $p$-cymene. However, no difference was found between $n$-hexane and isopropanol extracted oils regarding the content of this constituent. Besides, tocotrienols presented an inappreciable content in rapeseed oil. For sterols, no significant difference in composition and their relevant content was found among three extracted rapeseed oils (Table 5). $\beta$-Sitosterol, campesterol and brassicasterol were identified as the three major sterols in extracted rapeseed oils, among which brassicasterol was used to determine the adulteration of other oils.

\subsection{Theoretical solubility of various solvents}

Since HSP are available for limited numbers of standard solvents and solutes, it is interesting to introduce methods for predicting non-standard solvents and solutes only through their chemical structures. The useful prediction method proposed by Yamamoto was applied to calculate HSP of various solvents and constituents in extracted rapeseed oil due to its stability and high accuracy compared to other HSP estimation methods. The Yamamoto-Molecular Break (Y-MB) method breaks SMILES into

Table 3

The composition of fatty acids in various solvent-extracted rapeseed oils.

\begin{tabular}{|c|c|c|c|c|c|c|c|}
\hline Fatty acid composition & $n$-Hexane & Ethanol & Butanol & Isopropanol & $\alpha$-Pinene & p-Cymene & D-Limonene \\
\hline \multicolumn{8}{|l|}{ Saturated } \\
\hline C16:0 & $4.18 \pm 0.01$ & $4.72 \pm 0.01$ & $4.17 \pm 0.28$ & $4.14 \pm 0.40$ & $4.36 \pm 0.04$ & $4.40 \pm 0.02$ & $4.47 \pm 0.10$ \\
\hline C18:0 & $1.39 \pm 0.00$ & $1.27 \pm 0.02$ & $1.33 \pm 0.05$ & $1.35 \pm 0.09$ & $1.49 \pm 0.05$ & $1.56 \pm 0.07$ & $1.81 \pm 0.23$ \\
\hline C20:0 & $0.48 \pm 0.00$ & $0.43 \pm 0.03$ & $0.46 \pm 0.02$ & $0.47 \pm 0.01$ & $0.47 \pm 0.00$ & $0.47 \pm 0.00$ & $0.51 \pm 0.02$ \\
\hline $\mathrm{C} 22: 0$ & $0.31 \pm 0.04$ & $0.36 \pm 0.10$ & $0.24 \pm 0.34$ & $0.29 \pm 0.01$ & $0.26 \pm 0.00$ & $0.26 \pm 0.02$ & $0.27 \pm 0.03$ \\
\hline \multicolumn{8}{|l|}{ Mono-unsaturated } \\
\hline C16:1n-9 & $0.18 \pm 0.00$ & $0.26 \pm 0.01$ & $0.19 \pm 0.01$ & $0.18 \pm 0.03$ & $0.27 \pm 0.03$ & $0.20 \pm 0.01$ & $0.42 \pm 0.01$ \\
\hline C18:1n-9 & $57.98 \pm 0.29$ & $55.69 \pm 0.76$ & $57.75 \pm 0.16$ & $58.04 \pm 0.13$ & $58.13 \pm 0.03$ & $58.61 \pm 0.52$ & $57.32 \pm 1.11$ \\
\hline C20:1n-9 & $1.88 \pm 0.11$ & $1.53 \pm 0.13$ & $1.76 \pm 0.18$ & $1.82 \pm 0.21$ & $1.84 \pm 0.06$ & $1.78 \pm 0.12$ & $1.72 \pm 0.19$ \\
\hline$C 22: 1 n-9$ & $1.66 \pm 0.32$ & $1.24 \pm 0.28$ & $1.58 \pm 0.21$ & $1.50 \pm 0.33$ & $1.51 \pm 0.25$ & $1.43 \pm 0.36$ & $1.22 \pm 0.49$ \\
\hline \multicolumn{8}{|l|}{ Poly-unsaturated } \\
\hline C16:2 & $0.06 \pm 0.00$ & $0.09 \pm 0.00$ & $0.06 \pm 0.00$ & $0.05 \pm 0.01$ & $0.48 \pm 0.16$ & $0.06 \pm 0.00$ & $0.25 \pm 0.07$ \\
\hline C18:2n-6 & $22.20 \pm 0.17$ & $24.76 \pm 0.00$ & $22.64 \pm 0.12$ & $22.51 \pm 0.19$ & $21.87 \pm 0.08$ & $21.89 \pm 0.04$ & $22.57 \pm 0.01$ \\
\hline$C 18: 3 n-3$ & $9.54 \pm 0.04$ & $9.53 \pm 0.16$ & $9.60 \pm 0.05$ & $9.53 \pm 0.04$ & $9.22 \pm 0.06$ & $9.23 \pm 0.14$ & $9.33 \pm 0.00$ \\
\hline$C 20: 2 n-6$ & $0.13 \pm 0.01$ & $0.11 \pm 0.01$ & $0.11 \pm 0.01$ & $0.12 \pm 0.02$ & $0.11 \pm 0.00$ & $0.11 \pm 0.01$ & $0.12 \pm 0.00$ \\
\hline$\Sigma S F A s$ & 6.36 & 6.78 & 6.2 & 6.25 & 6.58 & 6.69 & 7.06 \\
\hline$\Sigma M U F A S$ & 61.7 & 58.72 & 61.28 & 61.54 & 61.75 & 62.02 & 60.68 \\
\hline$\Sigma P U F A s$ & 31.93 & 34.49 & 32.41 & 32.21 & 31.68 & 31.29 & 32.27 \\
\hline
\end{tabular}

PUFAs: polyunsaturated fatty acids; MUFAs: monounsaturated fatty acids; SFAs: saturated fatty acids. 
Version définitive du manuscrit publiée dans / Final version of the manuscript published in :

Comptes Rendus Chimie (2014), Vol. 17, p. 242-25, DOI: 10.1016/j.crci.201.3.09.002

Journal homepage: www.sciencedirect.com

corresponding functional groups and then estimates various properties.

The relevant physicochemical properties of various solvents were obtained by HSP calculation through their chemical structure, which were listed in Table 6. Alcohols have similar molecular weights and boiling points to $n$ hexane, while terpenes have similar molecular weights and chemical structures between each other. Terpenes and n-hexane had similar HSP values, whereas alcohols had different HSP with terpenes and hexane due to their hydroxyl group, which resulted in a higher $\delta_{\mathrm{h}}$. Moreover, terpenes and alcohols with higher dielectric constants had higher polarity and dissociating power than $n$-hexane. Besides, terpenes had higher flash points, which signified less flammable and less hazardous. The major drawback of using terpenes is their slightly higher viscosity and density,<smiles>CCCCCCCCCCCCCCCC(=O)O</smiles>

Palmitic Acid<smiles>CCCCCCCC/C=C/CCCCCCCC(=O)O</smiles>

Oleic Acid<smiles>CCCCC/C=C/C/C=C/CCCCCCCC(=O)O</smiles>

LinoleicAcid<smiles>CCC=CCC=CCC=CCCCCCCCC(=O)O</smiles>

LinolenicAcid<smiles>CCCCCCCCCCCCCCCCCC(=O)O</smiles><smiles>CCCCCCCCCCCCCCCCC(=O)O</smiles>

Stearic Acid<smiles>CCCCCCC=CCCCCCCCCC(=O)O</smiles>

EicosenoicAcid<smiles>CCC/C=C/C/C=C/CCCCCCCC(=O)O</smiles>

PalmitoleicAcid<smiles>CCCCCCCCCCCCCCCCCCCC(=O)O</smiles>

PalmitolenicAcid

Arachidic Acid<smiles>CCCCCC=CCC=CCCCCCCCCCC(=O)O</smiles>

Eicosadienoic Acid<smiles>CCCCCCCCCCCCCCCCCCCC(=O)O</smiles>

BehenicAcid

Fig. 3. Chemical structure of free fatty acids in extracted oils. 
Version définitive du manuscrit publiée dans / Final version of the manuscript published in :

Comptes Rendus Chimie (2014), Vol. 17, p. 242-25, DOl: 10.1016/j.crci.2013.09.002

Journal homepage: www.sciencedirect.com<smiles>Cc1c(C)c(C)c2c(c1C)CC[C@](C)(CCC[C@H](C)CCC[C@H](C)CCCC(C)C)C2</smiles><smiles>[B]c1c(Br)c(O)c(Br)c2c1OC(C)(CC/C=C(\C)CC(C)/C=C/CCC=C(C)C)CC2</smiles>

$\mathrm{R}=\mathrm{H}$ ar CH3

Tocotrienol

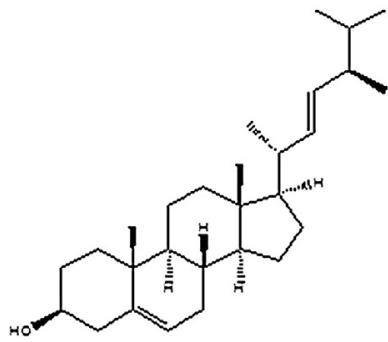

Brassicasterol<smiles>CC(C)C(C)CC[C@H](C)[C@]1(C)CC[C@]2(C)[C@]1(C)CC[C@]1(C)[C@@]3(C)CC[C@@H](O)CC3=CC[C@@]12C</smiles>

Campesterol

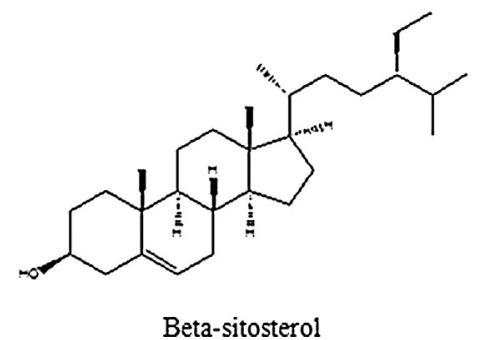

Fig. 4. Chemical structures for tocopherol, tocotrienol, and main sterols.

as well as the higher energy consumption in their recovery because of their high boiling point. It is worthy to mention that the solubility parameters of terpenes have generally been found more stable at higher temperatures than alcohols because of the hydroxyl group as well. With the consideration of all these points, terpenes could theoretically be considered better alternatives to $n$-hexane that alcohols in dissolving oils. All data in Table 6 also gave a good explanation for the small differences among different solvent-extracted oils regarding to their quantity and quality.

Two-dimensional graphs of $\delta_{\mathrm{p}}$ versus $\delta_{\mathrm{h}}$ have usually been used as references for easy understanding of the solubility of various solvent in Soxhlet extraction. As can be seen in Fig. 5, TAG in rapeseed oil was made up by three major identified fatty acids (C18:1n9, C18:2n6 and C18:3n3). All calculated HSP for various solvents and relevant constituents in extracted oils were used in plotting the Hansen solubility graph for theoretical prediction of appropriate solvents for extraction of rapeseed oil. It was clear to find that terpenes $\left(\delta_{\text {to- }}\right.$ tal $=17.1 \pm 0.5 \mathrm{MPa}^{1 / 2}$ ) had much smaller HSP distance to the triglyceride of rapeseed oil $\left(\delta_{\text {total }}=17.0 \mathrm{MPa}^{1 / 2}\right)$ and fatty acids $\left(\delta_{\text {total }}=17.7 \pm 0.4 \mathrm{MPa}^{1 / 2}\right)$ than that of alcohols $\left(\delta_{\text {to- }}\right.$ tal $\left.=23.57 \pm 1.63 \mathrm{MPa}^{1 / 2}\right)$. The same argument was obtained for tocopherol $\left(\delta_{\text {total }}=16.9 \mathrm{MPa}^{1 / 2}\right)$ and sterols $\left(\delta_{\text {to- }}\right.$ tal $\left.=17.6 \pm 0.2 \mathrm{MPa}^{1 / 2}\right)$. These predictions were in accordance with experimental results, which have further proved that terpenes could be preferential solvents for the extraction of oils from rapeseed as compared to alcohols. It is important to note that HSP can only help predict the solubility for better selection of appropriate solvents on the basis of thermodynamics rather than kinetics. Therefore, inconsistency may exist between experimental and theoretical results. Nonetheless, these divergences have insignificant influence on solvent selection for oil extraction from rapeseeds.

\subsection{Restrictions for agro-solvents development}

There are still many restrictions before considering industrial application of these new solvents for the extraction of vegetable oils. Firstly, the European regulation (Directive 2009/32) restricts the solvents used 
Version définitive du manuscrit publiée dans / Final version of the manuscript published in :

Comptes Rendus Chimie (2014), Vol. 17, p. 242-25, DOI: 10.1016/j.crci.201.3.09.002

Journal homepage: www.sciencedirect.com

Table 4

The content of tocopherol and tocotrienol in extracted rapeseed oils with $p$-cymene, isopropanol, and $n$-hexane.

\begin{tabular}{llll}
\hline & Isopropanol & $p$-Cymene & $n$-Hexane \\
\hline Tocopherols & & & \\
$\quad$ Acetate & $<5$ & $<5$ & $<5$ \\
Alpha & 315 & 107.5 & 291 \\
Beta & 3 & 3 & 2.5 \\
Gamma & 543.5 & 339 & 515.5 \\
Delta & 17.5 & 18 & 18 \\
Term vitamin (TE/100 mg) & 37.0 & 15 & 34.5 \\
Tocotrienols & & & \\
Alpha & & & \\
Beta & $<2$ & $<2$ & $<2$ \\
Gamma & $<2$ & $<2$ & $<2$ \\
Delta & $<2$ & $<2$ & $<2$ \\
Total (Tocopherol +Tocotrienol & 861 & $<2$ & $<2$ \\
Total uncertainty in & 129 & 533 & 879 \\
g/100g fatty matter & & 80 & 132 \\
\hline
\end{tabular}

Term vitamin: tocopherol content equivalent in vitamin E; TE: tocopherol equivalent; total uncertainty: standard deviation of analytical method is 0.15 .

for the extraction of foods, including the agro-solvents, which are generally not dangerous. Another limit is the recycling of the solvent. As described above, a large steam injection will take place in the desolventizer with an extended time. The desolvation technology must be adapted to reduce the retention of the marc solvent on the one hand and to work under the reduced pressure on the other hand, so that the working temperature can be reduced. In addition, other unknowns must be investigated. The stability and the non-reactivity of agrosolvents during many extraction/regeneration cycles need to be verified. The percolation of the solvent in
Table 5

The content of sterols in extracted rapeseed oils with $p$-cymene, isopropanol, and $n$-hexane.

\begin{tabular}{llll}
\hline Sterols & $\begin{array}{l}\text { Isopropanol } \\
(\%)\end{array}$ & $\begin{array}{l}p \text {-Cymene } \\
(\%)\end{array}$ & $\begin{array}{l}n \text {-Hexane } \\
(\%)\end{array}$ \\
\hline Cholesterol & 0.8 & 0.9 & 0.8 \\
Brassicasterol & 8.3 & 8.3 & 8.6 \\
24-methylene cholesterol & 1.1 & 1.1 & 1.1 \\
Campesterol & 37.6 & 37.6 & 38 \\
Campestanol & 0.2 & 0.4 & 0.3 \\
Stigmasterol & 0.2 & 0.3 & 0.2 \\
Delta 7 campesterol & 0.2 & $<0.1$ & $<0.1$ \\
Delta 5.23 Stigmastadienol & 0.5 & 0.6 & 0.5 \\
$\quad$ clerosterol & & & \\
Beta-sitosterol & 48.2 & 47.8 & 47.9 \\
Stigmastadienol & 0.2 & 0.3 & 0.2 \\
Delta 5 avenasterol & 2.1 & 2.1 & 1.9 \\
Delta 5.24 stigmastadienol & 0.4 & 0.4 & 0.3 \\
Delta 7 stigmasterol & 0.1 & 0.1 & 0.1 \\
Delta 7 avenasterol & 0.1 & 0.1 & 0.1 \\
Unindentified & $<0.1$ & $<0.1$ & $<0.1$ \\
Sterols in extracted & 941.8 & 894.11 & 897.03 \\
$\quad$ oils (mg/100g) & & & \\
\hline
\end{tabular}

an industrial extractor may be more difficult than that in the case of hexane if it managed to inflate the pressure cake. Furthermore, some used polymers such as seals or parts of pipes may have a poor performance in these new solvents. Unproblematic minor compounds in extracted oils may cause refinery problems as well.

Overall, most of the restrictions for using agro-solvents in extracting oilseeds can be raised through research and development. It is probable that the final cost of this new technology will be higher than that of the process with hexane, which may lead to the fact that industries would not to make technological innovations voluntarily without

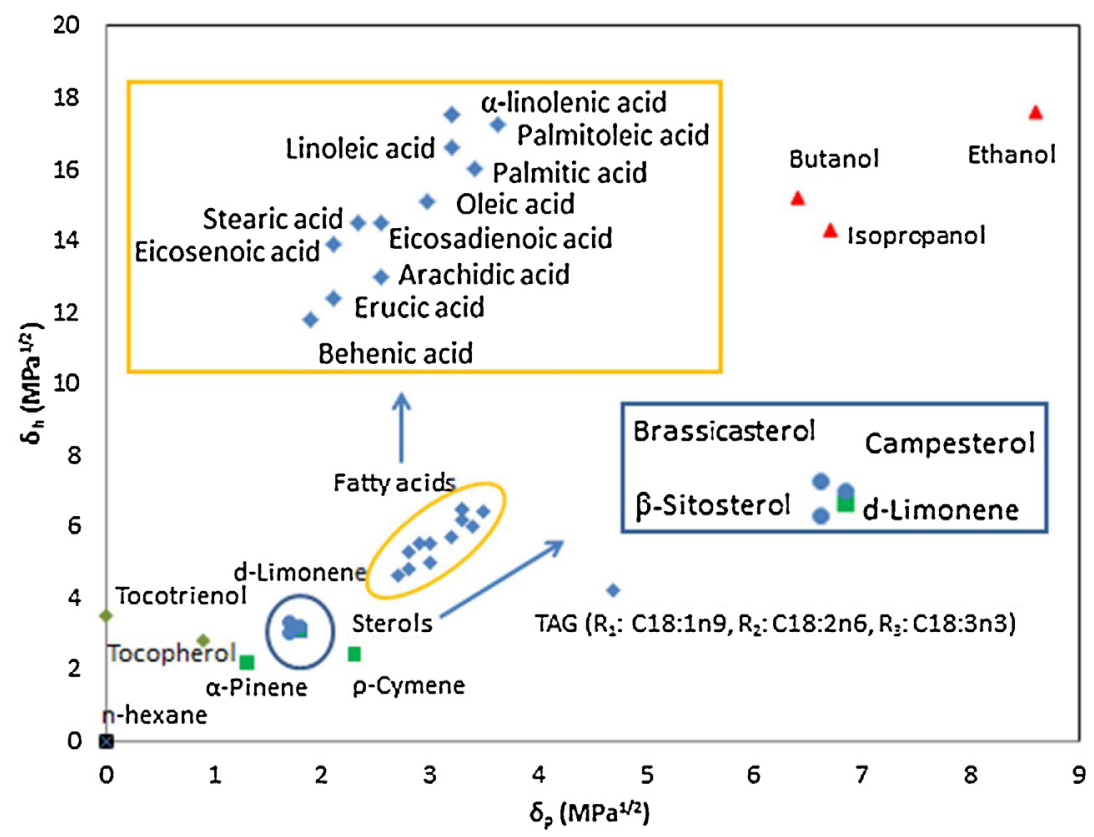

Fig. 5. Hansen two dimensional solubility parameters graphs of various solvents and main constituents in extracted oils: fatty acids ( $\bullet)$ and sterols $(\bullet)$ in extracted oils, terpenes $(\mathbf{\square})$, alcohols $(\mathbf{\Delta})$, and $n$-hexane $(\mathbf{\square})$. Color online. 
Version définitive du manuscrit publiée dans / Final version of the manuscript published in :

Comptes Rendus Chimie (2014), Vol. 17, p. 242-25, DOI: 10.1016/j̣.crci.2013.09.002

Journal homepage: www.sciencedirect.com

Table 6

Relevant physiochemical properties of various solvents and extracts.

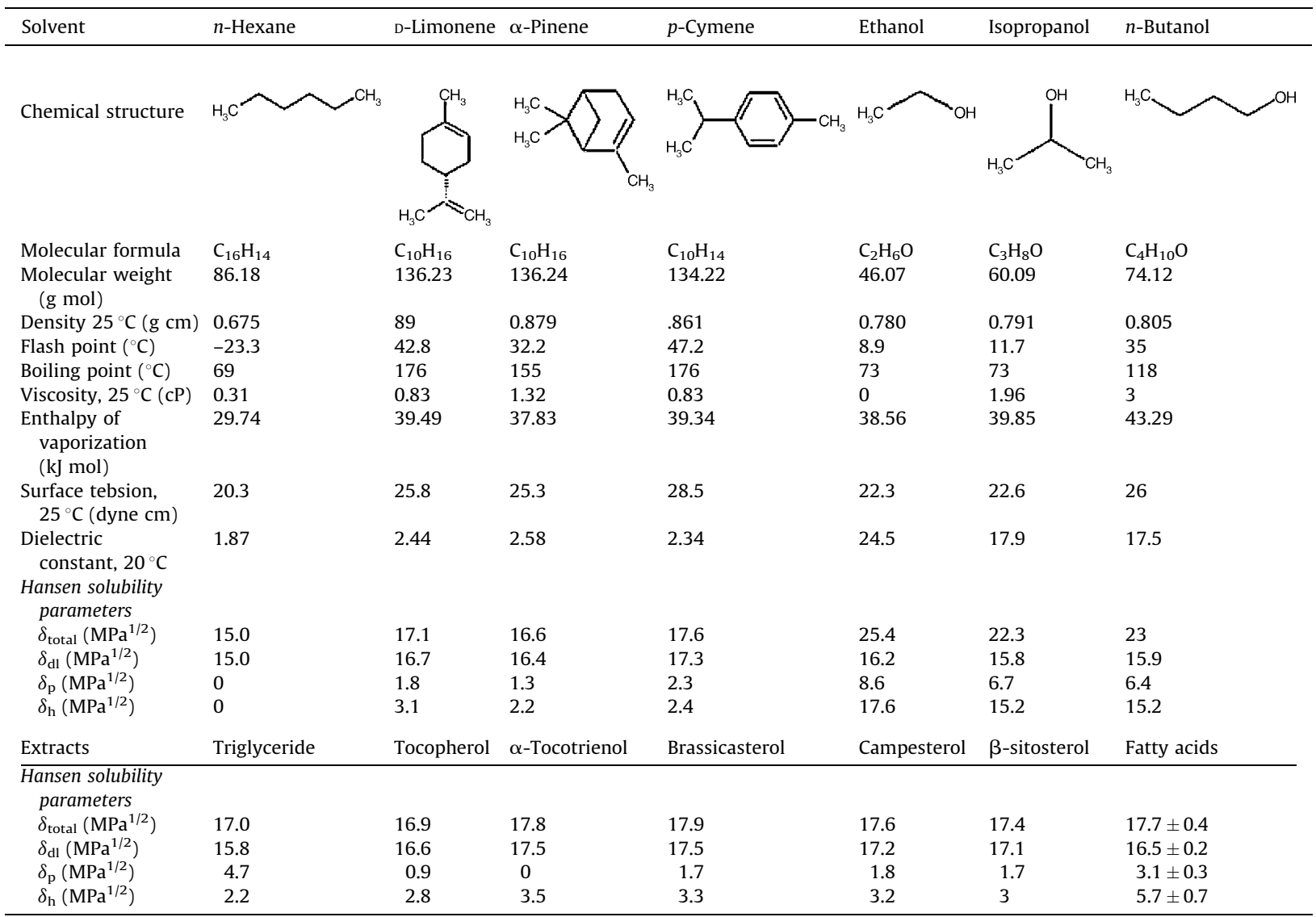

strong government incentives. However, it remains a possibility to produce enhanced oils that are desirable for consumers and reconcilable between industrial economy and government regulation.

\section{Conclusions}

It was theoretically and experimentally proved that $p$-cymene is the most promising solvent for $n$-hexane substitution in terms of its considerable extraction yield and selectivity. It could also extract more polar lipids, even if tocopherol and tocotrienol contents in its extracts were slightly lower. Although there are some limits to the use of alternative solvents such as European regulation on solvent used in food extraction and recycling, such solvents have already been developed in many industrial applications that have represented an interesting sustainable way to replace petroleum-origin solvents.

\section{Acknowledgements}

This work has been financed through Ecoleoprojet. Authors gratefully acknowledge the co-financial support from PACA (Provence-Alpes-Côte d'Azur) region in France and PEIFL (Pôle européen d'innovation fruits et légumes).

\section{References}

[1] R. Przybylski, T. Mag, N.A.M. Eskin, B.E. McDonald, in: F. Shahidi (Ed.), Bailey's Industrial Oil and Fat Products, 2, John Wiley \& Sons, Inc, New York, USA, 2005, p. 61.

[2] (a) T.P. Hensarling, T.J. Jacks, J. Am. Oil Chem. Soc 60 (1983) 783; (b) S. Kmieciak, S. Meziane, H. Kadi, R. Moussaoui, Grasas Aceites 42 (1991) 46

[3] (a) G.C. So, D.G. Macdonald, Can J Chem Eng. 64 (1986) 80; (b) S. Meziane, H. Kadl, O. Lamrous, Grasas Aceites 57 (2006) 175.

[4] M.B. Fernández, E.E. Perez, G.H. Crapiste, S.M. Nolasco, J. Food. Eng 111 (2012) 682-689.

[5] (a) P.J. Wan, R.J. Hron, M.K. Dowd, M.S. Kuk, E.J. Conkerton, J. Am. Oil Chem. Soc 72 (1995) 661;

(b) P. Hanmoungjai, L. Pyle, K. Niranjan, J. Chem. Technol. Biotechnol. 75 (2000) 348.

[6] M.R.J.R. Albuquerque, T.L.G. Lemos, O.D.L. Pessoa, E.P. Nunes, R.F. Nascimento, E.R. Silveira, Flavour Frag. J. 22 (2007) 249.

[7] ISO 659-1988 (E) in ISO-International Organization for Standardization, Geneva, 1988.

[8] (a) Amended AOCS Official Method Ca 5a-40, 1998;
(b) AOCS official methods Ce 1-62, 1998 ;
(c) AOCS Official Method Ce 2-66, 1997;
(d) NF EN ISO 12228, 1999;
(e) NF EN ISO 9936, 2006.

[9] Y. Li, F. Beisson, M. Pollard, J. Ohlrogge, Phytochemistry 67 (2006) 904.

[10] C.M. Hansen, J. Paint Technol. 39 (1967) 505.

[11] B. Olivier, B. Elisabeth, J. Food. Eng. 92 (2009) 396. 